International Journal of Social Science And Human Research

ISSN(print): 2644-0679, ISSN(online): 2644-0695

Volume 05 Issue 01 January 2022

DOI: $10.47191 /$ ijsshr/v5-i1-17, Impact factor-5.586

Page No: 112-121

\title{
Investigating the Moderating Effects of Social Wellbeing on the Relationship between Brand Identity and Fan Loyalty amongst Soccer Fans in America
}

\author{
J P Vansgaard ${ }^{1}$, Daniel J. A. Rhind ${ }^{2}$ \\ ${ }^{1,2}$ School of Sport, Exercise and Health ciences, Loughborough University, Loughborough, LE11 3TU
}

\begin{abstract}
This study builds on Funk and James (2001) and Bauer et al.'s (2008) attempts at modeling the relationship between brand identity and fan loyalty by examining the relationship in the context of fans of professional soccer in the United States. Social wellbeing is introduced into the model, answering the question "What are the moderating effects of social wellbeing on the relationship between brand identity and fan loyalty amongst fans of MLS?". A multiple regression analysis was done to verify the conceptual pathway delineated by Bauer et al. The results showed that the model accounted for $40.6 \%$ of the variance $\left(\mathrm{R}^{2}=.406\right)$ and the model encompassing both non-product and product related attributes did significantly predict fan loyalty, $\mathrm{F}(2,26)=9.341$, $\mathrm{p}=.000$. Additionally, non-product related attributes contributed significantly to the modelB $(\mathrm{B}=.034, \mathrm{p}=.475)$ while product attributes did not. Implications of the results are discussed.
\end{abstract}

KEY WORDS: brand image, brand awareness, social integration

\section{INTRODUCTION}

Researchers have been attempting to better understand sports fans' motivations, consumer interests, and loyalties in order to gain a more comprehensive understanding of a social phenomenon that has captivated millions of people worldwide. This captivation is at its most intense when it comes to soccer, the world's most popular sport, with the global soccer organization FIFA generating \$4.6 billion in 2018 (Tomlinson, 2018). Soccer has galvanized populations of die-hard supporters, particularly across Europe and South America, with fans likening their support of their favorite team to a religion, participating in violent run-ins with opposition fans, and at times being driven to suicide when their favorite team loses (Brown, 1998). This fever-pitch level of support for soccer has not quite reached the United States as of yet, but the market is growing, with NBC buying comprehensive rights to broadcast the English Premier League in 2013 (Sandomir, 2015) and finding support both in rankings and viewership (Bassam, 2020). The MLS, the United States' first division league, has enjoyed growth in viewership in-stadium support, with plans to introduce new franchises in the coming years, bringing the total number of franchises to 32 (Nicholson, 2019). As the sport grows in popularity in a new and sizeable market, unique opportunities for research present themselves. One such opportunity is to build on the work of prior researchers that have looked at the phenomenon of fan behavior, the benefits of participating in sport fandom, and the reasons why fans begin and continue supporting their teams over time.

The social benefits of sports fandom have been catalogued extensively in recent years, and the importance of the social benefits of sports fandom plays a significant part in determining fan loyalty, as Bauer et al.'s model and analysis confirms. This article will attempt to build on this knowledge by exploring the moderating effects that an individual's social wellbeing has on the parsimonious model of brand identity and fan loyalty established in their 2008 work. A better understanding of the role that one's social health plays in determining the strength and direction of one's loyalty as a fan can play a key role in the strategies various sports managers undertake in order to grow the long-term support of their brand, as well as rendering a wider social understanding of the role that sports teams and their fans effect the communities they are integrated in. Gathering data from fans in the United States provides a unique opportunity to examine the effects of social wellbeing on brand loyalty while the sport is in its relative infancy with regards to popularity in comparison to the rest of the Western World. As a consequence of examining the relationship in an earlier stage, a better understanding of how social wellbeing effects the relationship between brand identity and fan loyalty can have a larger impact in growing the popularity of the sport, as well as the potential positive social externalities that a soccer team can bring to a community.

\section{Fan Loyalty}

For the purposes of this project, the fan will be defined as those who are allegiant to specific sports or teams (Pooley, 1980). There 


\section{Investigating the Moderating Effects of Social Wellbeing on the Relationship between Brand Identity and Fan Loyalty amongst Soccer Fans in America}

has been some conjecture over the blanket nature of the term fan with some research detailing at length the nuanced and gradational nature of this term (Hewer, Gannon and Cordina, 2017; Holt, 1995, Wann and Branscombe, 1990). The behavioral component to fandom is also of importance in this study, both as a measure of identity and measurability. Sports marketing scholars have identified a multitude of behavioral components to sports fandom which will be incorporated into the functional definition of loyalty utilized in this paper.

The behavioral component of loyalty has been the primary source of measuring levels of fandom in much of sports marketing literature and social psychology (Bauer et al., 2008), due to its ease of measurement and salience of observable behaviors such as consumption when viewed within the team sports context. Spectator figures have been commonly cited as a barometer of this phenomena (Deschriver and Jensen, 2002; Funk, Mahoney and Ridinger, 2002; Beccarini and Ferrand, 2006; Wann and Branscombe, 1990). There are, of course, fans of a team whom are loyal but do not attend matches for a multitude of reasons, such as the surge in international popularity of some of the more successful European soccer clubs, causing fans to be unable to attend even if they would want to (Rein et al., 2006) and the rising salience of online fan communities and interventions such as social media taking a foothold in the marketing strategies of soccer teams in the modern day.

However, there is more to loyalty than mere behavior. Looking at the concept one dimensionally ignores nuances, as Backman and Crompton (1991) show with their illumination of the concept of spurious loyalty, which is seen in the fans that don't possess a strong positive attitude towards any team, but who nevertheless attend the matches on an ongoing basis. These examples aside, the trajectory amongst the literature is one that is attempting to go beyond such measurements and incorporate a more holistic lens to measure fan loyalty. Mahoney, Madrigal and Howard (2000) go so far as to say that the exclusive use of behavioral indicators that measure loyalty ignores the psychological processes that can give insights into the overarching concept of loyalty as a whole.

In order to address this limitation, the attitudinal component of loyalty will be used in this study as well. Attitudinal indicators refer to the psychological processes such as feelings of loyalty and commitment to a team (Bauer et al., 2008). Commitment in this context is defined as an emotional or psychological attachment to a brand (Beatty and Kahle, 1988). The brands in the context of this study are the professional soccer clubs competing in the MLS.

The attitudinal component of loyalty has been a theme central to past work on the topic, with attempts at measuring the concept in a team sports context by scholars Gladden and Funk (2001) and Mahoney et al. (2000). This line of research has led to three components of commitment surfacing as prominent: inner attachment, persistence and resistance. These components of commitment are deep seated psychological factors and are of particular relevance to sports marketers, as higher levels of these components lead to a level of loyalty that is more stubborn and less effected by variations in on field performance (Gladden and Funk, 2001).

Additionally, attitudinal measurements of loyalty are a better barometer of long-term loyalty, as attitudinal loyalty is more indicative of intrinsically motivated commitment, thereby helping to avoid cases of spurious loyalty.

Furthering the academic understanding of fan loyalty is of relevance to both sports marketers intending to grow their brand and build long-term support, but also to the potential fans themselves. There are several psychological reasons that an individual would want to become a fan of a certain team, namely the need to feel part of a distinct group (Branscombe et al., 1999) and the need to belong (Theodorakis et al., 2012). The need to belong can be described as the need to form and maintain strong, stable, interpersonal relationships, and in many psychological schools, is viewed as a fundamental innate motivation for human beings (Hornsey and Jetten, 2004; Pickett et al., 2004). Recent literature has pointed to the ability of sport fandom to fulfill that innate motivation. Sport fandom is a social activity (Schurr et al., 1998, Wann et al., 2001) and affiliation needs are often ranked as primary motivators for individuals engaging in sport fandom (Lee and Armstrong, 2008; Lee et al., 2005; Wann 1995). Sports fans also appear to use sport to satisfy social interaction needs (Mann, 1969).

Theodorakis et al. further investigated the relationship between the "need to belong" as an antecedent to sport team identification in an empirical study completed in 2012. Theodorakis et al. distributed a survey including questions addressing levels of general sport fandom and levels of sport spectatorship to a local basketball team. The other component of their survey assessed the participants' "need to belong." The researchers repeated this survey again in Greece to gain a cross-cultural comparison in an attempt to weed out any culture-dependent variables. The results indicated that the "need to belong" was significantly correlated with level of identification with a local team in both the American and Greek samples (Theodorakis et al., 2012). Although the results were merely correlational, it is significant in empirically testing the linkages of one of the positive social byproducts of sport fandom and team identification.

A deeper understanding of the mechanisms by which both the attitudinal and behavioral measures of loyalty can be increased could lead to more potentially loyal and committed fans, increasing accessibility to the social benefits that accompany it. One key variable that may be associated with fan loyalty is brand image.

\section{Brand Image}

Brand image is the form in which a brand is perceived by consumers. Certain brands in professional soccer have elevated their brand 


\section{Investigating the Moderating Effects of Social Wellbeing on the Relationship between Brand Identity and Fan Loyalty amongst Soccer Fans in America}

to global prominence, conveying a message that goes beyond their results on the pitch or the aesthetic nature of their play. Additionally, bolstering a club's brand image has been proven as a method of insulation from the financially detrimental effects of losses and poor on field performances (Gladden and Funk, 2001). As such, brand management has gained prominence amongst sports marketers and researchers in the United Kingdom, the United States and continental Europe. Brand identity is the operationalization of brand image, referring to how much a consumer identifies with the aspects of a given brand image (Bauer et al., 2008). Therefore, brand identity is the aspect of brand image that can be measured operationally.

There are two prominent empirical models that measure brand image. These models were developed by marketing scholars outside of the context of sport. Aaker (1991) proposed that the concept of brand equity is a synopsis of the advantages and disadvantages that a customer relates to a brand or symbol that drive the value of a product or service.

Keller's (1993) model draws on Aaker's conceptualization by further breaking down the concept of brand equity into two spheres, brand awareness and brand image. Brand awareness refers to a consumer's ability to recognize and recall a brand (Keller, 1993). Brand awareness is the first step to building associations that are tied to the brand node in memory. If brand awareness has not occurred, the various connections and associations that comprise brand identity cannot be made. (Bauer et al., 2008, p. 209). Understanding these associations is vital to the sports marketers who can create value outside of the core product itself by influencing the consumer's associations with his or her brand. In the marketing world, this creates a "bubble" for the core product, ensuring positive associations despite poor performances or quality on the field. Keller further suggests measuring brand associations via a three-pronged framework, consisting of the favorability, strength and uniqueness of brand associations in the consumer's memory. Keller's conceptualization has been measured in a sports context by Gladden and Funk $(2001,2002)$ by surveying committed fans across all the major American sports (58\% of respondents cited an American soccer team as their favorite team, 37\% baseball, $9 \%$ basketball and $4.9 \%$ hockey). In this heterogenous mixture of sports fans surveyed, Gladden and Funk performed a multiple regression analysis and found positive relationships between six brand association dimensions, including "product delivery," "escape," "nostalgia," "fan identification," and "brand loyalty," suggesting that higher scores of fan loyalty correlated to a greater emphasis on these associations. Interestingly, the negative scores were associated with star player and tradition, suggesting that the more loyal an individual, the less emphasis he or she attached to these particular brand association dimensions (Gladden and Funk, 2001, p.68).

These results, although fascinating, fail to recognize the differences of the sports and the subsequent difference in the values, perceptions, and attitudes of the people who become fans of them. Although there are similarities amongst sports fans regardless of the specific sport they are a fan of, perhaps more value could be found in further segmenting the study to individual sports in order to control for the potential differences amongst fans of each unique sport.

Bauer et al. made some conceptual adjustments to the model used by Gladden and Funk.

First of all, the primary variable measured in their study was brand identity, defined in their study as "the cumulative product of brand associations in the consumer's mind (Bauer et al., 2008, p. 209). Brand identity was measured by a model building on Keller's (1993) work. Bauer et al. made a further adjustment to the model by adding in measures indicating the strength, favorability and uniqueness of each brand attribute. Bauer et al. further classified brand attributes into product and non-product related attributes. Following their classification, the category of product related attributes consisted of elements constituting the core product of the sports team such as head coach, star player, success and team play. Non- product related attributes included elements still related to the brand but not direct components of the team itself. These attributes include a club's history and tradition, logo and club colors, and fan identification to name a few (Bauer et al., p. 227). The consumer's perceived benefits of these attributes were also measured. Noteworthy examples of the benefits measured include peer group acceptance, escape, socializing and companionship, emotions, nostalgia and entertainment.

In addition, shifting the conceptual focal point from Gladden and Funk's model, Bauer et al. kept their study to fans of a single sport, professional soccer, by surveying fans the German Bundesliga exclusively. This shift in operationalization is a key one in the conceptual pathway leading to this study, which will be focusing solely on American soccer fans.

Bauer et al.'s survey and subsequent analysis suggested that the effect of the non-product related attributes on perceived fan benefits was almost triple that of non-product related benefits (Bauer et al., p. 222). Following this conceptual model, this means that the benefits of non- product attributes such as fan identification, socializing and companionship play a much more vital part in determining fan loyalty when compared to product related attributes. Although this may seem surprising, these findings are consistent with prior research examining brand associations in team sports, explaining, for example, consistent levels of support amongst sports teams despite poor results during matches (King and Mullin, 2000; Bauer, Sauer and Schmidt, 2004).

Bauer et al. conclude their study by making recommendations for sports marketers.

According to the researchers, sports marketers can increase levels of fan loyalty by improving the aspects of non-product related attributes of their teams, specifically by "fostering contact with other fans and cultivating the team's tradition (Bauer et al., p. 227)." Bauer et al. continue to recommend that "sports clubs should emphasize the creation and conservation of fan loyalty through well 


\section{Investigating the Moderating Effects of Social Wellbeing on the Relationship between Brand Identity and Fan Loyalty amongst Soccer Fans in America}

planned interactions designed to deliver extraordinary experiences (Bauer et al., p. 222)."

Bauer et al.'s adjustments and insights into the conceptualization of the measurement of brand image as well as their finding that emphasize the importance of fostering meaningful and quality interactions amongst fans to increase fan loyalty are key theoretical springboards for this study.

In the following section, the literature surrounding the relationship between soccer fandom and its connection to social health and wellbeing will be reviewed.

\section{Social Connection and its Impact on Wellbeing}

The concept of social integration can be thought of as the relationship between social ties and individual health (Berkman et al., 2000). According to Berkman et al., (2000) there are two theorists who have contributed the most to the field of understanding the relationship between social ties and individual health, Durkheim and his work on social integration, alienation and anomie, and John Bowlby's work on attachment theory.

Durkheim's "Suicide" explains the relationship between social cohesion, social integration and mortality, with an aim to illustrate how individual pathology was interrelated to social dynamics (Berkman et al., 2000). In his work, Durkheim identified four types of suicide: egoistic, altruistic, anomic and fatalistic (Pickering and Walford, 2000). Egoistic suicide cases would come about as a result of an individual's poor integration within a community, leading to a rise in meaninglessness so profound that the individual decides to take his own life (Harriford and Thompson, 2008). Durkheim found that these individuals were not sufficiently integrated to social groups, and therefore did not benefit from the guidance, support and companionship that those groups thereby provided. Durkheim found that unmarried men were particularly susceptible to this type of suicide (Thompson, 1982).

John Bowlby forward attachment theory, another theoretical base that has served as a building block for much of the modern work on social integration and mental wellbeing (Storr, 1991). Attachment theory contends that a healthy form of attachment of infants to their mothers provides a critical jumping off point from which that infant can venture forth and create meaningful relationships outside of familial protection (Bowlby, 1969). Bowlby states that "secure attachment provides an external ring of psychological protection which maintains the child's metabolism in a stable state, similar to the internal homeostasis mechanism of blood pressure and temperature control." Bowlby saw marriage as an adult extension of that childhood need for attachment, equating one's spouse in adulthood to one's mother during infancy, providing that the role of a social base from which to explore the outer social world with confidence and without fear, thus leading to other lasting and loving relationships.

Bowlby and Durkheim's contributions to the field of social connection and mental health prove that an individual's mental health is inextricably tied to their connections with other human beings (Berkman et al., 2000). The complexities of that relationship have been studied since, and much has been discovered, particularly in the "downstream" manifestations of the health consequences and benefits studied in lonely or disconnected individuals. These include avenues of social support, (typically divided into subtypes of emotional, informational, appraisal, and instrumental support [Weiss, 1974]), social influence (referring to the influence one's peers or social group has on one's health behaviors such as smoking, exercising, drinking, etc.), social engagement (providing opportunities for networking as well as enhancing the quality of already existing relationships), and person to person contact (related specifically to the exposure of disease vectors).

The works of Durkheim and Bowlby illustrate that individual and social wellbeing go hand in hand. In the following section, we will examine the mechanisms by which participation in sport fandom can influence one's social wellbeing.

\section{Soccer Fandom and Social Wellbeing}

There are various social theories which attempt to explain the ways in which social participation in group activities such as sport spectatorship affect social wellbeing. Hogg and Abrams examined the importance of the demarcation and affirmation of an in-group and the necessary foil of an out-group with which the in-group compared itself to. Their resulting 'social identity theory' refers to a person's knowledge that they belong in a social category or group (Hogg and Abrams, 2006). According to this theory, individuals seek to define themselves in terms of their immersion in relationships with others and with larger collectives and derive much of their self-valuation from such social identities (Hogg and Abrams, 2006) In other words, one's individual identity, and the selfworth or lack thereof that it brings to that individual, is contingent on one's favorable position within an in-group. This desire to fit favorably in an in- group has even been referred to as "the essence of social identity" (Pelham, 1995).

Additionally, sociologist Robert Putnam's theory of social capital outlines the declining trend of civic engagement in the United States, particularly evident in the sharp decrease in voluntary participation in community groups such as sports teams, union membership, and parent teacher schooling organizations, to name a few. This trend, according to Putnam, is damaging the social fabric of communities within the United States, leading to significant drops in levels of social trust (Putnam, 2000). Less social participation within communities leads to less opportunities to produce social capital, defined as "features of social organization such as networks, norms and social trust that facilitate coordination and cooperation for a mutual benefit."

Various sociologists have examined the effects of Putnam's theory of social capital creation and sport. Delaney and Keaney (2005) have analyzed the relationship between the extent of the involvement in sport and the level of social capital across Europe, 


\section{Investigating the Moderating Effects of Social Wellbeing on the Relationship between Brand Identity and Fan Loyalty amongst Soccer Fans in America}

analyzing how sport contributes to bridging social bonds and more active citizenship. Strong correlations between extent of involvement in sport and the levels of social trust and well-being were found as well (Delaney \& Keaney, 2005).

\section{Research Question and Aims}

Expanding upon the lineage of studies focusing on brand equity in team sport Gladden and Funk, 2001) and refined under the context of professional soccer in the Bundesliga (Bauer et al, 2008), this study intends to introduce the variable of social wellbeing into the equation comprising brand identity and fan loyalty. The social nature of soccer fandom and the various benefits it brings to social health have been extensively documented in various cultural and empirical contexts, but there remains a gap between the marketing research surrounding brand equity in soccer and the social benefits of sports fandom examined by Wann, Branscombe and others. This research intends to be a bridge by which sports marketers can better understand the non-product related benefits that accompany being a fan of a professional soccer team.

This study will utilize the conceptual model and method of measurement utilized by Bauer et al. in their study on the relationship between brand identity and fan loyalty in professional soccer. This relationship will be examined amongst a population of MLS fans in the United States, providing a cross-cultural example to which the German study can be compared. Additionally, a measure of social wellbeing will be introduced, established by social psychologist Keyes (1998). The moderating effects of social wellbeing on the relationship between identity and fan loyalty will then be examined in order to answer the question, "What are the moderating effects of social wellbeing on the relationship between brand identity and fan loyalty amongst fans of the MLS?"

\section{METHODOLOGY}

\section{Operationalizing Fan Loyalty}

The construct of fan loyalty was adopted from Bauer et al.'s 2008 study. Bauer et al. broke down their measurement of loyalty into two dimensions: behavioral loyalty and psychological commitment, which represented the attitudinal component of loyalty (p. 215). The constructs measuring psychological commitment were adopted from the Psychological Commitment to a Team Scale (PCT), developed by Mahoney, Madrigal and Howard (2000) and from the TAM developed by Gladden and Funk (2001). Bauer et al. added two items measuring the importance of the future welfare of the club, an aspect that was left out of earlier conceptual renditions. This aspect of fan loyalty was adapted from Garabarino and Johnson's Commitment Scale (1999). A mean scale score for loyalty was calculated and used as a dependent variable in the study. This mean scale score incorporated both the attitudinal and behavioral components of loyalty.

\section{Operationalizing Brand Identity}

The construct of brand identity was also adopted from Bauer et al.'s 2008 study. In their study, brand equity of the sports clubs studied was broken down into brand attributes. Brand attributes were subsequently further broken down into product and nonproduct related attributes. The strength, favorability and uniqueness regarding these attributes is then measured. Mean scale scores were calculated for both product and non-product related attributes, respectively. These mean scale scores were then used for analysis.

\section{Participants}

In order to fill the criteria for this study, the participants had to be active fans from teams in the MLS. Participants were therefore recruited from fan forums on the social media platform, Reddit. Subscribers from each team's unique fan forum volunteered to take part after an invitational prompt was posted on the forum wall.

The total number of respondents who answered the survey came to a total of 324 . The initial batch of responses yielded a total of 267 usable responses, as 57 responses were unable to be utilized due to being incomplete or fans having indicated that their favorite team was outside of the MLS. Given that the respondents were recruited from highly active fan forums during the offseason, the sample utilized in this study is biased towards more committed fans. Because higher levels of commitment could lead to higher levels of fan loyalty, this was considered to be advantageous.

Fifty-three percent of the respondents were aged 20-29, with the average age of respondents being 30 years old. As expected, the majority of the respondents were male (88.4\%). The average level of education was higher than average, with $42.2 \%$ of respondents reporting having received a bachelor's degree, $16.6 \%$ having received a master's degree, and only $3.1 \%$ not having received a high school diploma. The respondents were a mixture of fans from all MLS teams. The teams with the most fans represented in the survey were Atlanta United (31) and the Colombus Crew (21).

\section{Survey}

In order to measure the moderating effects of social wellbeing on the relationship between brand image and fan loyalty in professional soccer amongst fans in the MLS, a survey was created.

This survey contained operationalizations of the constructs discussed previously. Participants were firstly ensured of their anonymity and asked for their consent before beginning to participate. Respondents then filled out general demographic information. 


\section{Investigating the Moderating Effects of Social Wellbeing on the Relationship between Brand Identity and Fan Loyalty amongst Soccer Fans in America}

Participants then answered questions taken from Keyes' Social Wellbeing Scale (1998). This scale measures social wellbeing across five dimensions: social integration, social contribution, social coherence, social actualization, and social acceptance. The Social Wellbeing Scale has a high reliability and validity and has been used in prior studies regarding social wellbeing amongst sports fans (Wann et al., 2009).

This scale included a total of thirty items (six questions for each of the five dimensions) and each response was measured by Likert Scale responses with a range from 1 to 7 . A sample question from this scale asks the participate to indicate how strongly they'd agree with a statement such as the following: "Your community is a source of comfort," or "You think you have something of value to give to the world." An aggregate mean score was calculated for each of the respondent's answers across the SWS and used for the subsequent analysis.

Participants were then asked to indicate their favorite soccer team via a write in response. Respondents whom indicated that their favorite team was outside of the MLS had their responses invalidated and were not utilized in the analysis. Once their favorite teams were indicated, their levels of loyalty to that team were measured on a seven-point Likert scale. Aggregate scores were then used for analysis.

Brand identity was then assessed. Again, responses were measured on a seven-point Likert scale. Participants were asked to indicate their opinions on the strength, favorability, and uniqueness of each brand attribute. Attributes were divided intro product and non-product related in keeping with the structure utilized in Bauer et al.'s 2008 study. Aggregate scores calculated for each of the two attribute subcategories and were utilized for the subsequent analysis.

\section{Analysis}

Mean scale scores were computed for social wellbeing, fan loyalty, and product and non-product related attributes. As all items were measured on the same seven-point Likert Scale, no further transformation of the variables was necessary to begin the analysis.

A multiple regression analysis was first conducted between the attributes that comprised brand identity and the computed mean scale score for fan loyalty. This was done to ensure that the relationships amongst the constructs were consistent with Bauer et al.'s findings, therefore validating the data as a basis for further analysis. Prior to conducting the multiple regression analysis, various preconditions for the regression were conducted and met. These preconditions included ensuring that the relationship between product and non-product related attributes and fan loyalty was linear, making sure that there was no multicollinearity in the data, checking for homoscedasticity, ensuring normally distributed residuals, and checking for outliers (Osborne and Waters, 2012). The results of the multiple regression will be discussed in the following section.

After the multiple regression was conducted and the model was formed, the moderating effects of social wellbeing on said model was examined. Hayes' "Process" macro was utilized for this analysis. This macro is reliable and has been used frequently in many academic studies (Hayes and Rockwood, 2017). The results of the moderation analysis will be discussed in the following section.

\section{RESULTS}

\section{Does brand image significantly predict fan loyalty in the data collected?}

The results of the regression analysis indicated that the regression model explained $40.6 \%$ of the variance $\left(\mathrm{R}^{2}=.406\right)$ and that the model encompassing both non-product and product related attributes was indeed a significant predictor of fan loyalty, $\mathrm{F}(2,26)=$ $9.341, \mathrm{p}=.000$. Similar to the results of Bauer et al.'s regression analysis, it was found that non-product related attributes contributed significantly to the model $(\mathrm{B}=.034, \mathrm{p}=.475)$, thereby reaffirming the relationship between the constructs of brand identity and fan loyalty as catalogued in Bauer et al.'s study. The final predictive model was as follows:

Fan Loyalty $=2.373+(.034 \times$ product related attributes $)+(.600 \times$ non-product related attributes

\begin{tabular}{llccll}
\hline Model & $\begin{array}{l}\text { Sum } \\
\text { Squares }\end{array}$ & ofdf & Mean Square & F & Sig. \\
\hline Regression & 76.024 & 2 & 38.012 & 90.36 & $.000^{\mathrm{b}}$ \\
\hline Residual & 111.334 & 264 & .422 & \\
\hline & & & ANOVA & \\
\hline Total & 187.358 & 266 & & & \\
\hline
\end{tabular}

a Dependent Variable: fan loyalty

bPredictors: (Constant), np_related_attributes, p_related_attributes,

Figure 1: ANOVA table: Multiple Regression 

amongst Soccer Fans in America

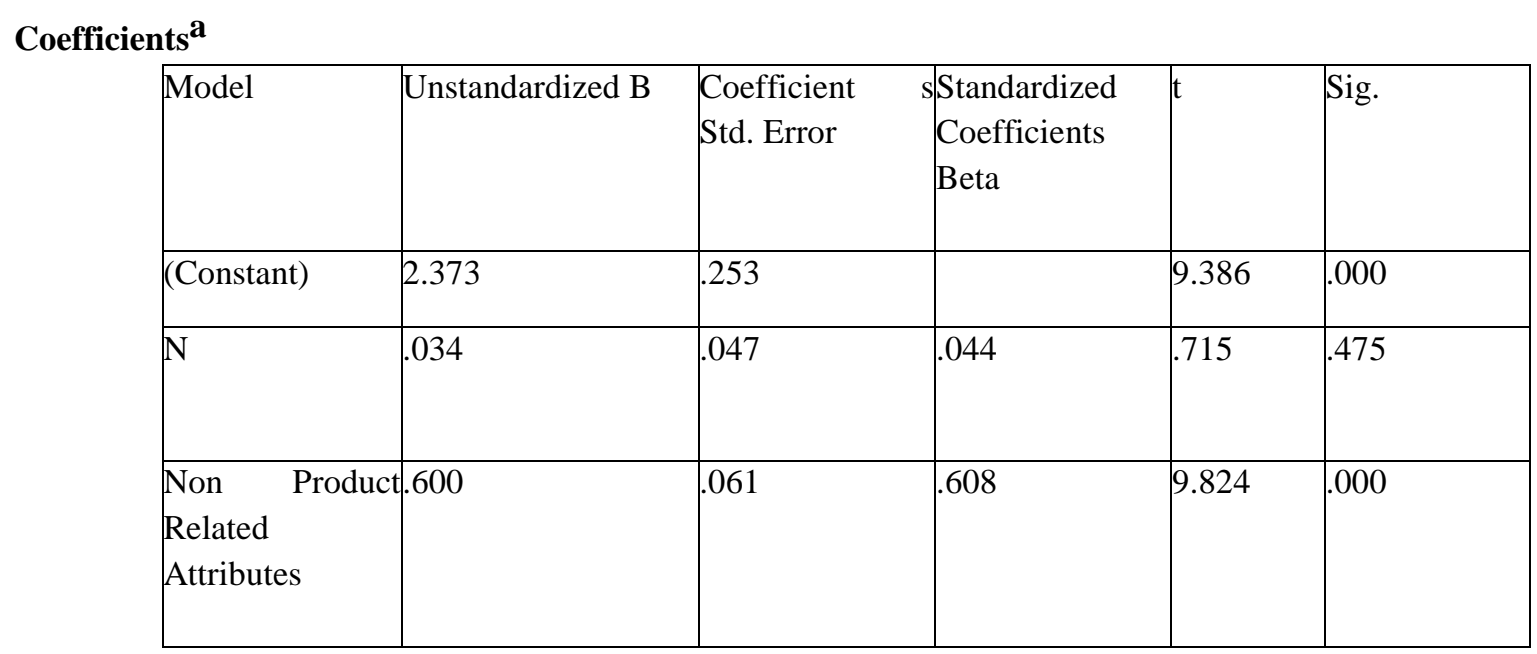

Figure 2: Coefficients Table: Multiple Regression

Does social wellbeing significantly moderate the relationship between brand image and fan loyalty amongst soccer fans in the MLS?

Once the initial predictive model was confirmed as significant via a multiple regression analysis, the moderation analysis was performed. After running Hayes' "Process" macro in SPSS, the following table was generated:

\section{MODEL SUMMARY}

\begin{tabular}{|l|l|l|l|l|l|l|}
\hline Model & coeff & se & t & p & LLCI & ULCI \\
\hline constant & -.5660 & 1.6468 & -3.433 & .7317 & -3.8122 & 2.6803 \\
\hline bidentit & 1.0723 & .3043 & 3.5723 & .0005 & .4731 & 1.6725 \\
\hline swbs & .6667 & .3505 & 1.9022 & .0582 & -.0234 & 1.3568 \\
\hline Int_1 & -.1006 & .0639 & -1.5745 & .1166 & -.2264 & .0252 \\
\hline
\end{tabular}

Figure 3: Model Summary table: Moderation

As seen in the table, the moderating interaction is described in the line labelled "Int_1." Judging by the confidence interval columns, it can be said that social wellbeing did not have a significant moderating effect on the relationship between brand identity and fan loyalty, as the range between the two confidence intervals included 0 (LLCI $=2.2264$, ULCI $=.0252$ ) $($ Hayes, 2012). Therefore, after running a moderation analysis it can be concluded that social wellbeing is not a significant moderator on the relationship between brand identity and fan loyalty amongst fans of the MLS.

\section{DISCUSSION}

Each of the two findings from both analyses lend important insights into the relationship between brand identity and fan loyalty amongst fans of professional soccer in the MLS. Firstly, the insights provided by Bauer et al. in their analysis of the aforementioned relationship rings true amongst a different cultural sample; the perceived benefits of non-product related attributes play a far more important role in the creation of fan loyalty than do the perceived benefits of product related attributes. This relationship holds true despite the vast cultural differences between German and American fans, especially with regards to soccer. The German Bundesliga is a far more storied and established league in the MLS, with prominent teams such as Bayern Munich having been established at the turn of the 20th century (1900) and has enjoyed vast European successes and grown into an international brand. The values of German soccer are held very dearly by fans and professionals with private ownership being permitted only as recently as 1998 . Additionally, the "50+1 Rule" was implemented in order to maintain the fans as an integral part of the ownership and direction of German soccer clubs more generally (Scheuber, 2017). In contrast, fans of the MLS are not as historically or culturally invested in soccer as their German counterparts. The league experienced a period of excruciatingly low attendance and disillusionment from fans from the late 1990s to the early 2000s, with the league going so far as to change the mechanics of the sport to make it more "American," such as adding hockey-style shootouts to determine the outcome of matches ending in a draw. These tweaks did not 


\section{Investigating the Moderating Effects of Social Wellbeing on the Relationship between Brand Identity and Fan Loyalty amongst Soccer Fans in America}

bring in new fans and instead alienated the already established ones (Rivera, 2014). Although the league has made a resurgence in recent years, its attendance figures pale in comparison to the German Bundesliga; the Bundesliga's average attendance in the 2018/19 season was 43,358 compared to 21,875 in the MLS (Borg, 2018).

Despite the gulf in cultural importance and the comparatively young life of soccer in the United States, it is still intriguing to see that non-product related attributes such as club history and tradition play such an important part in generating fan loyalty, while the values of sport traditionally associated with American sport such as star player, success, and head coach were nearly insignificant in comparison. The consistency of the relationship between product and non- product related attributes in the creation of fan loyalty across vastly different cultural contexts brings into question the salience of culture in the formation of fan loyalty. Investigating the role that the salience of culture plays in the development of fan loyalty amongst soccer fans presents an interesting avenue for future research. The relationship between brand image and fan loyalty should be studied cross-culturally in order to give more insights on the role that the sport of soccer's presence in a given culture plays on how attributes are interpreted by fans.

The other significant implication from this study can be gleaned from the results of the moderation analysis, whereby the moderating influence of social wellbeing on the relationship between brand identity and fan loyalty was examined. This is the first study in which social wellbeing as measured by Keyes' Social Wellbeing Scale (1998) has been used in the context of fan loyalty and marks another step in understanding the social aspects of soccer fandom.

One relevant instance of incorporating social wellbeing and the SWS into a sports fandom context is Wann and Weaver's 2009 study examining the hypothesized relationship between fan-team identification and social wellbeing. Wann and Weaver found that a stronger identification with a local team was positively related to social wellbeing, specifically to the subcategories of social wellbeing concerning social integration and social coherence (Wann and Weaver, 2009). Wann and Weaver's findings coupled with a multitude of studies verifying the linkages between social-psychological wellbeing and identification (Delaney and Keaney, 2005; Jarvie, 2003; Tonts 2005; Hiannis, 1998; Funk and James, 2001; Branscombe et al., 1999) set the stage for social wellbeing to have an important role to play in influencing the link between brand identity and fan loyalty. However, the results of the moderation analysis ran contrary to the expectations set by the conclusions of previous studies, as social wellbeing failed to moderate the relationship between brand identity and fan loyalty in a significant manner.

This finding has implications in both the business and social realms. From a business perspective, while the influence that a strong fan identity has on loyalty is undeniable and is again evidenced by this study, unduly efforts to portray the soccer team as a remedy to one's

feelings of social isolation or disconnect is not advisable. Instead, marketers should target and bolster avenues by which connections to both club culture and other fans can be established and strengthened.

It can be postulated that the manner in which social media has revolutionized the methods by which fans interact with their teams has a part to play in explaining the lack of the significant moderating influence of social wellbeing on brand identity and fan loyalty. As the criteria of what constitutes being a loyal fan shifts from the physical interactions with the spaces and people connected to a given club to a more amorphous, internet-based identity, the linkages between the fan and the physical aspects of community may continue to diminish. Future research should examine the ways that the traditional location-based notion of fandom and fan loyalty has changed due to the now ubiquitous presence of social media in the experience of soccer fans.

Although this study has contributed to the literature, it is not without its limitations. Firstly, aggregate scores for social wellbeing were used for the analyses performed. Future research would do well to incorporate Wann and Weaver's idea of analyzing the predictive power of each of the five sub- components of social wellbeing, as measured by Keyes's Social Wellbeing Scale (1998). Doing so would give a more nuanced insight into which particular aspects of social health (e.g. social integration, social acceptance, and social actualization, social coherence, social contribution) effect the relationship between brand identity and fan loyalty.

Additionally, the sample utilized in this study was intentionally constrictive, sampling only committed fans of teams in the MLS in order to glean insights into the nature of fan loyalty amongst fans of a sizeable yet relatively untapped market. Future research should expand the samples studies to include fans of different cultures and levels of commitment in order to gain more a conclusive snapshot of the width and depth of soccer fandom around the world.

Finally, this study only examined the moderating effects of social wellbeing on one aspect of fan loyalty. The effects of social wellbeing on aspects of fan loyalty such as attachment (Funk and James, 2006) and identification (Funk and James, 2001; Wann and Branscombe, 1993; Sutton et al., 1997) amongst soccer fans should also be examined. Perhaps one's social- psychological health could have greater moderating influences on other established relationships in the conceptualization of fan loyalty.

\section{CONCLUSION}

This study builds on Bauer et al.'s (2008) conceptual model of the relationship between brand identity and fan loyalty by examining the relationship using a different cultural sample, that of committed fans of the MLS. Bauer et al.'s findings of the importance of non-product related attributes such as club history, tradition and fan identity were mirrored in the sample utilized for this study. A 


\section{Investigating the Moderating Effects of Social Wellbeing on the Relationship between Brand Identity and Fan Loyalty amongst Soccer Fans in America}

moderation analysis was then performed by introducing the moderating variable of social wellbeing into the established relationship between brand identity and fan loyalty. The moderating effects of social wellbeing were not found to be significant.

These findings provide insights into the role of the cultural significance of soccer in a given society when conceptualizing fan loyalty, as regression analyses showed that non-product related attributes played just as important a role in the modeling of fan loyalty amongst American soccer fans as it did in the German sample despite the sport playing a much smaller role in the cultural and social lives of Americans. Consequently, clubs should continue to increase the accessibility and quality of fan engagement practices such as club-sponsored meet ups and facilitate the creation and participation of fans in club-related internet forums and social media in order to increase positive associations with non-product related attributes. Additionally, social wellbeing's nonsignificant role in moderating the relationship between brand identity and fan loyalty highlight the changing nature of what constitutes being a loyal fan in a time where connections to the physical places represented by soccer clubs could be transitioning into a more remote, internet based experience due to the influence of social media and online mediums of fan support. Traditional measures of behavioral loyalty such as attending matches in a stadium could begin to be replaced with other metrics, such as the number of tweets tweeted during a match or amount of club-related Instagram posts.

Future research should build on the results shown in this paper by analyzing the different interactions of each of the five specific components of social wellbeing and how they contribute not only to fan loyalty but other aspects of soccer fandom such as attachment and team identification, as well as incorporating cross cultural samples of differing levels of commitment in order to gain a more conclusive understanding of the aspects influencing fan loyalty amongst fans of professional soccer. Doing so would benefit sports marketers as well as fans by

developing marketing strategies that target the social and emotional needs of the supporters of a club, allowing both parties to enjoy the positive ramifications associated with a loyal fanbase.

\section{REFERENCES}

1) Aaker, D.A. (1991). Managing brand equity: Capitalizing on the value of a brand name. New York: Free Press.

2) Abrams, D., \& Hogg, M. A. (2006). Social identifications: A social psychology of intergroup relations and group processes. Routledge.

3) Backman, S.J., \& Crompton, J.L. (1991, Fall). Using loyalty matrix to differentiate between high, spurious, latent, and loyal participants in two leisure services. Journal of Park and Recreation Administration, 9, 1-17.

4) Bauer, H. H., Stokburger-Sauer, N. E., \& Exler, S. (2008). Brand image and fan loyalty in professional team sport: A refined model and empirical assessment. Journal of sport Management, 22(2), 205-226.

5) Bauer, H.H., Sauer, N.E., \& Schmitt, P. (2004). Die Erfolgsrelevanz der Markenstärke in der 1.

6) Fußball-Bundesliga. [Customer-based brand equity and its impact on the economic success in the German "Bundesliga"]. (Working Paper, Institute of Market-Oriented Management). Mannheim, Germany: University of Mannheim Press.

7) Beatty, S.E., \& Kahle, L.R. (1988). Alternative hierarchies of the attitude behavior relation- ship: The impact of brand commitment and habit. Journal of the Academy of Marketing Science, 16, 1-10.

8) Bowlby, J. (1997). Attachment. Random House. Cultural isolation and the schizophrenic personality. (1934). American Journal of Sociology, 40(2), 155-164. https://doi.org/10.1086/216681

9) Bowlby, J. (1969). Attachment and loss v. 3 (Vol. 1). Random House. Furman, W., \& Buhrmester, D.(2009). Methods and measures: The network of relationships inventory: Behavioral systems version. International Journal of Behavioral Development, 33, 470- 478.

10) Branscombe, N.R., Ellemers, N., Spears, R. and Doosje, B. (1999) 'The context and content of social identity threat', in Ellemers, N., Spears, R. and Doosje, B. (Eds.): Social Identity, pp.35-58, Blackwell, Oxford, UK.

11) Brown, A. (Ed.). (1998). Fanatics!: Power, identity, and fandom in soccer. Psychology Press. Delaney, L., \& Keaney, E. (2005). Sport and social capital in the United Kingdom: Statistical evidence from national and international survey data. Dublin: Economic and Social Research Institute and Institute for Public Policy Research, 32.

12) DeSchriver, T.D., \& Jensen, P.D. (2002). Determinants of spectator attendance at NCAA Division II soccer contests. Journal of Sport Management, 16, 311-330.

13) Funk, D.C. and James, J. (2001) 'The psychological continuum model: a conceptual framework for understanding an individual's psychological connection to sport', Sport Management Review, Vol. 4, No. 2, pp.119-150.

14) Funk, D.C., Mahony, D.F., \& Ridinger, L.L. (2002). Characterizing consumer motivation as individual difference factors: Augmenting the sport interest inventory (SII) to explain

15) Garbarino, E., \& Johnson, M. (1999). The different roles of satisfaction, trust, and commit- ment in customer relationships. Journal of Marketing, 63(2), 70-87.

16) Giulianotti, R., \& Robertson, R. (2009). Globalization and soccer. Sage. 
17) Harriford, D., \& Thompson, B. (2008). When the center is on fire: Passionate social theory for our times. University of texas Press.

18) Harvey, A. (2013). The emergence of soccer in nineteenth-century England: The historiographic debate. The International Journal of the History of Sport, 30(18), 2154-2163.

19) Hayes, A. F., Montoya, A. K., \& Rockwood, N. J. (2017). The analysis of mechanisms and their contingencies: PROCESS versus structural equation modeling. Australasian Marketing Journal (AMJ), 25(1), 76-81.

20) Hewer, P., Gannon, M., \& Cordina, R. (2017). Discordant fandom and global soccer brands: 'Let the people sing'. Journal of Consumer Culture, 17(3), 600-619.

21) Holt, R. (1995). Contrasting nationalisms: sport, militarism and the Unitary State in Britain and France before 1914. The International Journal of the History of Sport, 12(2), 39-54. Human Kinetics.

22) Hornsey, M. J., \& Jetten, J. (2004). The individual within the group: Balancing the need to belong with the need to be different. Personality and Social Psychology Review, 8(3), 248-264.

23) Keller, K.L. (1993). Conceptualizing, measuring and managing customer-based brand equity. Keyes, C. L. M. (1998). Social well-being. Social psychology quarterly, 121-140.

24) level of spectator support. Sport Marketing Quarterly, 11, 33-43.

25) Lee, D. and Armstrong, K.L. (2008) 'Gender differences in the factors influencing viewership of televised sports', International Journal of Sport Management, Vol. 9, No. 1, pp.46-66.

26) Mann, L. (1969) 'Queue culture: the waiting line as a social system', American Journal of Sociology, Vol. 75, No. 3, pp.340-354

27) Mullin, B.J., Hardy, S., \& Sutton, W.A. (2007). Sport marketing (3rd ed.). Champaign, IL: Nicholson, P. (2019, November 22). Garber says MLS will stick at 32 teams as he headlines

28) Soccerex USA opening day. Inside World Soccer. http://www.insideworldsoccer.com/2019/11/22/garber-says-mls-willstick-32-teams- headlines-soccerex-usa-opening-day/

29) Pickering, W. S., \& Walford, G. (Eds.). (2000). Durkheim's Suicide: a century of research and debate (Vol. 28). Psychology Press.

30) Pooley, J. C. (1980). The sport fan: A social-psychology of misbehaviour. Canadian Association for Health, Physical Education and Recreation.

31) Putnam, R. D. (2001). Bowling alone. Simon \& Schuster.

32) Rein, I., Kotler, P., \& Shields, B. (2006). The elusive fan: Reinventing sports in a crowded marketplace. McGraw-Hill.

33) Sandomir, R. (2015). NBC retains rights to Premier League in six-year deal. Retrieved August, 10, 2015.

34) Sawe, B. E. (2016). The Most Popular Sports in the World. World Atlas, 16. Storr, A. (1991). The dynamics of creation. Penguin Books Ltd.

35) Sutton, W.A., McDonald, M.A., Milne, G.R. and Cimperman, J. (1997) 'Creating and fostering fan identification in professional sports', Sport Marketing Quarterly, Vol. 6, No. 1, pp.15-22.

36) Theodorakis, N. D., Wann, D. L., Nassis, P., \& Luellen, T. B. (2012). The relationship between sport team identification and the need to belong. International Journal of Sport Management and Marketing, 12(1-2), 25-38.

37) Theodorakis, N. D., Wann, D. L., \& Weaver, S. (2012). An antecedent model of team identification in the context of professional soccer. Sport Marketing

38) Tomlinson, A. (2014). FIFA (Fédération internationale de soccer association): the men, the myths and the money. Routledge.

39) Tonts, M. (2005). Competitive sport and social capital in rural Australia. Journal of Rural Studies, 21, 137-149.

40) Wann, D. L. (2006). Understanding the positive social psychological benefits of sport team identification: The team identification-social psychological health model. Group Dynamics: Theory, Research, and Practice, 10(4), 272

41) Wann, D. L., \& Branscombe, N. R. (1990). Die-hard and fair-weather fans: Effects of identification on BIRGing and CORFing tendencies. Journal of Sport and Social issues, 14(2), 103-117.

42) Wann, D. L., \& Weaver, S. (2009). Understanding the Relationship between Sport Team Identification and Dimensions of Social Well-being. North American Journal of Psychology, 11(2).

43) Wann, D.L. (2006) 'The causes and consequences of sport team identification', in Raney, A.A. and Bryant, J. (Eds.): Handbook of Sports and Media, pp.331-352.

44) Wann, D.L., Melnick, M.J., Russell, G.W. and Pease, D.G. (2001) Sport Fans: The Psychology and Social Impact of Spectators, Routledge Press, New York. 